\title{
Descrição macroscópica e topografia do intestino grosso da paca (Cuniculus paca Linnaeus, 1766)
}

\author{
Camila Paes Bürger* \\ Márcia Rita Fernandes Machado \\ Karina Paes Bürger \\ Faculdade de Ciências Agrárias e Veterinárias, Campus de Jaboticabal, UNESP \\ Via de Acesso Prof. Paulo Donato Castelanne s/n, CEP 14884-900, Jaboticabal - SP, Brasil \\ *Autor para correspondência \\ ca_birg@hotmail.com
}

Submetido em 05/09/2011

Aceito para publicação em 03/01/2012

\section{Resumo}

O alto potencial zootécnico para a exploração da paca implica no aporte de informações sobre a morfofisiologia do trato digestório para adequada implementação do manejo nutricional. O intestino grosso da paca foi investigado em seus aspectos morfológicos e topográficos, mediante inspeção de peças a fresco e fixadas em solução aquosa de formaldeído a 10\% provindas do plantel do Setor de Animais Selvagens do Departamento de Zootecnia da Faculdade de Ciências Agrárias e Veterinárias de Jaboticabal - UNESP (FCAV - UNESP). Este segmento, na paca, é formado pelo ceco, cólon e reto, situa-se na cavidade abdominal e pélvica a partir das terceira ou quarta vértebras lombares. Com isso, constatou-se que, nas 10 amostras analisadas, não houve variação no padrão de disposição do intestino grosso, e que este padrão se assemelha ao dos mamíferos em geral.

Palavras-chave: Intestino grosso; Morfologia; Paca; Topografia

\section{Abstract}

Gross morphology and anatomy of the large intestine of the paca (Cuniculus paca Linnaeus, 1766). Exploring the potential of using the paca as livestock involves understanding the morphophysiology of its digestive tract so its nutrition can be properly managed. The morphological and anatomical aspects of the large intestine of this species were investigated by inspecting material that was fresh and fixed in an aqueous solution of $10 \%$ formaldehyde. The material was provided by the Setor de Animais Selvagens do Departamento de Zootecnia da Faculdade de Ciências Agrárias e Veterinárias de Jaboticabal - UNESP (FCAV - UNESP). The large intestine of the paca is formed by cecum, colon and rectum, and is located in the abdominal and pelvic cavity near the third or fourth lumbar vertebrae. It was found, in the 10 samples analyzed, that there was no change in the pattern of this arrangement and that this pattern resembles that of mammals in general.

Key words: Large intestine; Morphology; Paca; Topography 


\section{Introdução}

Os roedores caviomorfos, como as pacas (Cuniculus paca), são uma importante fonte de proteína para a população humana rural da América tropical (COIMBRA FILHO, 1974; COLLET, 1981). Juntamente com as cutias (Dasyprocta sp.), esses animais são citados como um dos principais itens da dieta dessa população e, consequentemente, os mamíferos de pequeno porte mais caçados nessas regiões. Este desfrute de proteína animal de alta qualidade está baseado em extrativismo puro, não havendo controle ou manejo dessas espécies (KLEIMAN et al., 1979).

Para Schwarze e Schröder (1972), podem ser identificadas distintas porções no intestino grosso dos animais domésticos mediante sua forma, situação de seu meso, ligamentos e vascularização. Este consiste do ceco, cólon com três subdivisões e reto (NICKEL et al., 1979; BARONE et al., 1986; DYCE et al., 2010).

A porção inicial deste segmento, o ceco, aparece como um apêndice entre o intestino delgado e o cólon (SCHWAZE; SCHRÖDER, 1972; NICKEL et al., 1979; BARONE et al., 1986; DYCE et al., 2010). No cavalo, ruminantes e carnívoros, está situado à direita, entretanto no suíno se localiza à esquerda (SCHWARZE; SCHRÖDER, 1972; NICKEL et al., 1979; BARONE et al., 1986). A curvatura menor do ceco se encontra próxima, a desembocadura do íleo, e o orifício de saída do cólon em situação lateral e caudal (SCHWARZE; SCHRÖDER, 1972; BARONE et al., 1986).

Nos herbívoros e nos onívoros, o ceco é bem distinto e espesso, particularmente amplo (BARONE et al., 1986; SIMMONS, 2002; BRESSAN et al., 2005). Para Rodbertus (2002), todos os roedores, com única exceção do dormice (Graphiurus angolenses), possuem um ceco, frequentemente de extenso comprimento e saculado, como nas lebres (Lepus europaeus), rato d'água (Nectomys squamipes) e porco espinho (Hystrix cristata).

Nos animais domésticos e lagomorfos, o ceco está fixado pela sua continuação com o íleo e com o cólon, e, de maneira indireta, pelos mesos destes órgãos. Além disso, está unido ao íleo pela prega ileocecal, geralmente curta e de forma triangular. O resto de sua extensão é geralmente livre e o ápice é flutuante (BARONE et al., 1986).

Quanto à segunda divisão do intestino grosso nos mamíferos domésticos, como descrita por Schwarze e Schröder (1972), Nickel et al. (1979) e Dyce et al. (2010), esta apresenta três porções diferenciadas. A primeira divisão se estende desde o ceco até a região cranial da artéria mesentérica cranial e denomina-se cólon ascendente. Na sequência, a segunda porção corre obliquamente, desde o antímero direito até o esquerdo e se denomina cólon transverso. A terceira e última porção, denominada cólon descendente, está representada pela porção que prolonga o cólon transverso até a pelve. Para Barone et al. (1986), o cólon, nos mamíferos domésticos, constitui a maior parte do intestino grosso.

O reto é a parte final do intestino grosso sendo alongado na metade dorsal do coxal comunicando-se com o exterior mediante o canal anal (BARONE et al., 1986; SIMMONS, 2002). É lhe dado como limite cranial parte do ísquio e é assim chamado, pois não possui nenhuma circunvolução. Sua superfície externa é lisa e desprovida de nódulos e a sua face dorsal é sempre convexa e segue a curvatura do sacro, a qual é menos pronunciada nos mamíferos que no homem (BARONE et al., 1986).

Para García e Silva (2000), o intestino grosso é muito desenvolvido na paca, caracterizando-se como um grande ceco que se continua com o cólon, a qual apresenta uma zona de aspecto sacular, continuação direta do ceco. Logo continua uma porção tubular reta que gradualmente se adelgaça originando uma parte em forma de espiral, zona na qual as partes variam de diâmetro, sendo umas grossas e outras delgadas. Aúltima zona deste segmento apresenta formato ligeiramente elipsoidal, correspondendo ao cólon sigmóide.

Assim, o objetivo deste trabalho foi descrever macroscópica e topograficamente o intestino grosso das pacas, pois a literatura é escassa no que se refere à morfologia do sistema digestório desses animais. 


\section{Material e Métodos}

Foram utilizados dez animais adultos, machos, com variação de peso entre 10 a $12 \mathrm{~kg}$, provenientes do plantel do Setor de Animais Selvagens do Departamento de Zootecnia da Faculdade de Ciências Agrárias e Veterinárias de Jaboticabal - UNESP (FCAV - UNESP). Os animais utilizados foram a óbito por motivos diversos, cuja causa não comprometeu as estruturas estudadas neste projeto.

Dos dez animais, $50 \%$ foram destinados para os estudos macroscópicos em peças a fresco e o restante fixado em solução aquosa de formaldeído a $10 \%$. Os animais não fixados foram posicionados em decúbito dorsal e, por meio de incisão pré-retro-umbilical com o rebatimento lateral das paredes abdominais, as estruturas desta cavidade foram expostas com especial atenção ao intestino grosso.

Em sequência, foram identificados topograficamente os segmentos desta porção intestinal.

Os animais fixados em solução aquosa de formaldeído a $10 \%$ foram colocados em decúbito lateral direito para rebatimento da parede abdominal esquerda, juntamente com o membro pélvico esquerdo e, desta forma, proporcionar uma melhor visualização das estruturas contidas nas cavidades abdominal e pélvica, favorecendo a avaliação topográfica in situ.

\section{Resultados}

Após a abertura das cavidades abdominal e pélvica, a partir da terceira ou quarta vértebra lombar, constatouse que o intestino grosso destes roedores é formado pelo ceco, cólon, reto e canal anal (Figura 1).

O ceco iniciou-se após desembocadura do íleo e caracterizou-se pela forma sacular, alargada em seu início e, que em seguida, curvou-se e dobrou-se em direção crânio caudal terminando em um pequeno ápice posicionado na região medial e caudal da cavidade abdominal na altura correspondente a quarta ou quinta vértebras lombares.

$\mathrm{Na}$ mesma altura da desembocadura do íleo, em direção oposta ao ceco, iniciou-se o cólon maior, segmento intestinal curvado em forma de "s", que a princípio, circundou dorsal e ventralmente o ceco.

O cólon descendente (maior) seguia em direção ao plano médio, na porção caudal da cavidade abdominal, onde formou uma estrutura espiralada, semelhante ao cólon maior dos ruminantes, embora esta espiral, na paca, tenha apresentado apenas um giro e meio centrípeto e um giro e meio centrífugo.

Em sequência, a alça centrífuga seguiu em sentido dorsal e, aproximadamente na altura da segunda ou terceira vértebra lombar, prosseguiu em um pequeno cólon transverso. Este seguiu em direção ao antímero esquerdo, continuando como cólon descendente (menor), estrutura esta, que na paca, diferenciou-se por apresentar uma porção inicial na forma de um cólon flutuante, exibiu em sua porção inicial, um meso agregado, determinando uma concentração da alça intestinal, que em seguida, tomou forma tubular e seguiu caudalmente, terminando no reto.

FIGURA 1: Fotomacrografia da cavidade abdominal da paca, com exposição do antímero esquerdo rebatido, na qual se visualiza parte do ceco (Ce) e parte do cólon maior (CM), na altura da terceira vértebra lombar (Seta).

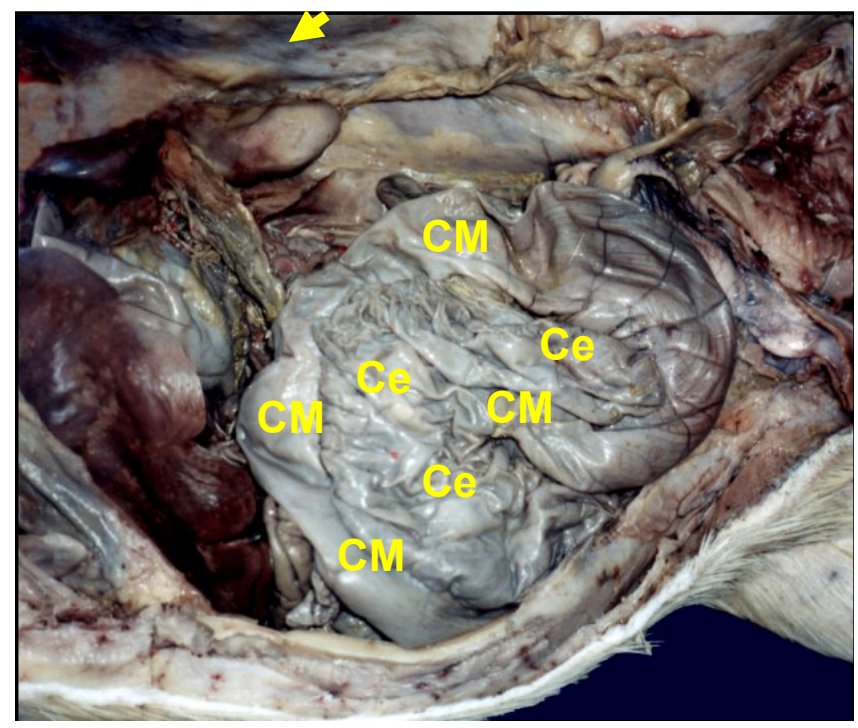

Ao examinar a vista ventral da cavidade abdominal aberta das pacas estudadas e correlacionar a topografia do intestino grosso desses animais com a porção cranial da cavidade abdominal (epigástrica, subdividida em xifóide e hipocondríacas direita e esquerda), com a porção média 
(mesogástrica, subdividida em umbilical e laterais, direita e esquerda) e com a porção caudal (hipogástrica, subdividida em púbica e inguinais, direita e esquerda), constatou-se que o intestino grosso destes animais estendeu-se por todas estas regiões. Considerando ainda a correlação em questão, uma vez que o ceco e o cólon se iniciavam a partir da desembocadura do íleo, na altura da quarta e da quinta vértebras lombares, considerou-se assim, o início do intestino grosso na região umbilical da cavidade abdominal.

O ceco era bastante desenvolvido, ocupando parcialmente as regiões xifóide, lateral direita, lateral esquerda, umbilical, inguinal esquerda e púbica. Após seu início na região umbilical, dirigiu-se caudalmente até a região púbica, curvou-se e voltou cranialmente pela região lateral esquerda, em direção à região xifóide, onde se curvou novamente, em direção caudal. Seu ápice estava localizado na altura da região umbilical.

O cólon maior iniciou-se juntamente com o ceco na região umbilical, curvou-se cranialmente e voltou-se para a direita, seguindo pela região lateral direita caudalmente, até a região púbica, tomando posição dorsal ao ceco e dirigindo-se cranialmente, formando uma espiral na altura da região lateral direita. $\mathrm{O}$ giro centrífugo desta espiral seguiu transversalmente formando o cólon transverso na altura da primeira vértebra lombar, em posição cranial da região umbilical. Este segmento intestinal dirigiu-se à esquerda, continuando-se em cólon menor, que se estendeu desde a região hipocondríaca esquerda até a região inguinal esquerda; seguindo caudalmente, adentrando na cavidade pélvica da mesma forma que o reto.

Observando a junção do íleo ao intestino grosso mediante secção desses segmentos intestinais, observouse que o íleo desembocou entre o ceco e o cólon formando uma projeção que separa estes segmentos intestinais.

Sobre os meios de sustentação do intestino grosso da paca constatou-se a presença das pregas íleo cecal, íleo cólica e ceco cólica (Figura 2). Notou-se também um meso entre o duodeno e cólon transverso; um mesocólon envolvendo o segmento espiralado do cólon maior; um meso bem desenvolvido no cólon flutuante.
O último segmento intestinal observado foi o reto, localizado na cavidade pélvica, cujo meio de sustentação era o meso reto.

O comprimento médio de cada porção que constituiu o intestino grosso da paca foi de $32 \mathrm{~cm}$ para o ceco; $101 \mathrm{~cm}$ para o cólon maior; $12 \mathrm{~cm}$ para o cólon transverso, $234 \mathrm{~cm}$ para o cólon menor e $10,5 \mathrm{~cm}$ para o reto.

FIGURA 2: Fotomacrografia do íleo (I), ceco (Ce) e cólon (Co) de uma paca adulta, onde se observam as pregas íleo cecal (Ice), íleo cólica (Ico), ceco cólica (Cco).

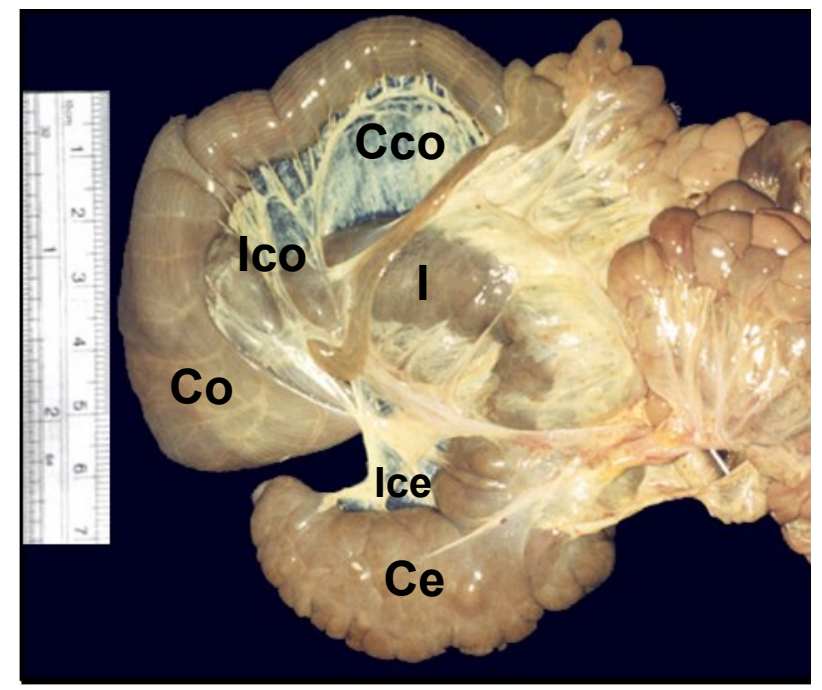

\section{Discussão}

As observações sobre o intestino grosso da paca revelaram, tal qual as descrições realizadas para os animais domésticos (SCHWARZE; SCHRÖDER, 1972; NICKEL et al., 1979; SISSON, 1981 apud GETTY, 1986; BARONE et al., 1986), para o rato e camundongo (SMALLWOOD, 1992) e para o rato (SIMMONS, 2002), uma localização abdomino-pélvica para este segmento intestinal, situando-se na altura das terceira e quarta vértebras lombares; sendo que, como descrito por Oliveira et al. (2006), a paca possui 13 vértebras torácicas, seis lombares, quatro sacrais e de sete a nove caudais. Os autores supracitados indicaram também uma divisão em porções, as quais foram denominadas de ceco; cólon ascendente, transverso e descendente; reto e canal anal, sendo estas porções determinadas mediante a forma, localização e a situação dos mesos. 
Não se verificou na paca a presença de um cólon sigmóide caudal ao cólon menor como foi observado no coelho (BARONE et al., 1986) e na própria paca conforme descrição de García e Silva (2000).

Da mesma forma que ocorre nos mamíferos domésticos (SCHWARZE; SCHRÖDER, 1972; NICKEL et al., 1979; BARONE et al., 1986; DYCE et al., 2010) e no coelho (BARONE et al., 1986) o segmento inicial do intestino grosso da paca era o ceco, o qual iniciava-se na desembocadura do íleo (SCHWARZE; SCHRÖDER, 1972; NICKEL et al., 1979; BARONE et al., 1986; DYCE et al., 2010); na paca, este segmento se colocava por toda cavidade abdominal, corroborando com os achados em coelhos (QUIRILO et al., 2006) e diferenciando do que ocorre nos animais domésticos (SCHWARZE; SCHRÖDER, 1972; NICKEL et al., 1979; BARONE et al., 1986; DYCE et al., 2010; BOWEN, 2002) e na cobaia (BANKS, 2002), pois nestas espécies, o ceco, se restringe às regiões laterais, direita ou esquerda, da cavidade abdominal.

O grande volume cecal da paca também descrito por García e Silva (2000), provavelmente deve-se ao seu hábito alimentar, característico de herbívoros e onívoros (NICKEL et al., 1979; BARONE et al., 1986; DYCE et al., 2010; BRESSAN, 2005), de coelho (BARONE et al., 1986), rato e camundongo (SMALLWOOD, 1992; SIMMONS, 2002), chinchila (Chinchilla lanígera) (CASTRO et al., 2010) e roedores de clima árido (JACKSON; SPINKS, 1998). Semelhantemente ao coelho (BARONE et al., 1986), o ceco da paca circundava-se sobre si mesmo, da esquerda para a direita, formando uma espiral. Sua principal característica era a forma sacular tal qual observado por Rodbertus (2002) em vários roedores e por García e Silva (2000); também na paca, o ceco mostrava-se alargado em seu início em concordância às descrições de Barone et al. (1986) e Dyce et al. (2010) para os animais domésticos, e de Banks (2002) para a cobaia. A terminação do ceco, na paca, dava-se em forma de ápice estreito, posicionado caudalmente em direção à pelve. Tal posição cecal assemelha-se à dos ruminantes, dos suínos e dos carnívoros (SCHWARZE; SCHRÖDER, 1972), quanto ao ápice, este se encontrava livre na cavidade abdominal, na altura correspondente às quarta ou quinta vértebras lombares, situação esta que não foi citada detalhadamente por nenhum dos autores consultados.

Sobre o cólon maior, na paca, este segmento iniciava-se no ceco logo após a desembocadura íleo-cecal, da mesma forma que ocorre nos animais domésticos (SCHWARZE; SCHRÖDER, 1972; NICKEL et al., 1979; BARONE et al., 1986). A porção inicial do cólon maior na paca flexionava-se em forma de "s" achatado tal qual acontece nos ruminantes (SCHWARZE; SCHRÖDER, 1972). Na paca, a continuação deste segmento sigmóide, formava uma espiral, na qual, a alça intestinal determinava um giro e meio no sentido centrípeto e um giro e meio no sentido centrífugo, não se encontrou na literatura compilada relato semelhante a este tipo de mensuração, embora, este formato espiralado do cólon maior assemelhouse ao dos ruminantes (SCHWARZE; SCHRÖDER, 1972; NICKEL et al, 1979), do coelho (BARONE et al., 1986); do hamster e do rato d'agua (Rodbertus, 2002), da própria paca (GARCÍA; SILVA, 2000), diferenciando-se, entretanto do modelo encontrado em suínos (SCHWARZE; SCHRÖDER, 1972) no qual se observa uma dupla espiral. Na paca, a alça centrífuga deste segmento espiralado do cólon maior continuava-se em cólon transverso, passando do antímero direito para o antímero esquerdo, da mesma forma que é descrito para os mamíferos (SCHWARZE; SCHRÖDER, 1972; NICKEL et al., 1979; BARONE et al., 1986; CASTRO et al., 2010; DYCE et al., 2010), esta transição ocorre no nível da segunda ou terceira vértebras lombares diferentemente das citações de Sisson (1981, apud GETTY, 1986) para os equinos.

$\mathrm{Na}$ paca, em sequência ao cólon transverso, continuava-se o cólon menor, que se apresentava com um meso bastante desenvolvido, semelhantemente ao do coelho (BARONE et al., 1986) e do equino (SCHWARZE; SCHRÖDER, 1972; NICKEL et al., 1979; BARONE et al., 1986; DYCE et al., 2010).

Tal qual ocorre nos animais domésticos (SCHWARZE; SCHRÖDER, 1972; NICKEL et al., 1979; BARONE et al., 1986; DYCE et al., 2010), no coelho (BARONE et al., 1986), no rato e no camundongo (SMALLWOOD, 1992; SIMMONS, 2002), no porco espinho e no castor canadense (Castor canadensis) 
(VISPO; HUME, 1995), na própria paca (GARCÍA; SILVA, 2000), na chinchila (CASTRO et al.,2010) e em vários roedores (RODBERTUS, 2002), o último segmento do intestino grosso da paca é o reto sendo a continuação do cólon descendente em direção à cavidade pélvica (NICKEL et al., 1979).

No que se refere à topografia do intestino grosso da paca, ao se analisar o aspecto ventral da cavidade abdominal desses animais em relação às regiões anatômicas desta cavidade (NICKEL et al., 1979; SCHALLER, 2007), constatou-se que o intestino grosso destes animais se estendia desde a região umbilical, componente da região abdominal cranial até a região pélvica componente da região caudal.

Assim, na paca, o ceco ocupava parcialmente as regiões xifóide, lateral direita, lateral esquerda, umbilical, inguinal esquerda e púbica, discordando das informações referentes aos animais domésticos nos quais este segmento ocupa apenas as regiões ao lado do plano mediano (NICKEL et al., 1979) e do coelho o qual ocupa apenas a região xifóide e umbilical (QUIRILO et al., 2006).

O cólon maior, na paca, iniciava-se juntamente com o ceco na região umbilical do abdome, e também ocupava as regiões lateral direita e púbica; o cólon transverso encontrava-se na região umbilical e o cólon menor seguia pela região hipocondríaca esquerda e inguinal esquerda semelhantemente ao que acontece nos animais domésticos e no coelho (BARONE et al., 1986; QUIRILO et a., 2006). O último segmento do intestino grosso da paca, o reto, seguia caudalmente, adentrando na cavidade pélvica como o descrito por Nickel et al. (1979) nos animais domésticos.

Sobre os meios de sustentação do intestino grosso da paca constatou-se a presença da prega ileocecal entre o íleo e o ceco, íleocólica entre o íleo e o cólon maior e cecocólica entre o ceco e o cólon maior. Observou-se também, entre duodeno e o cólon transverso, um meso cólon envolvendo o segmento espiralado do cólon maior, um meso bem desenvolvido no cólon menor. No último seguimento, o reto, notou-se um meio de sustentação denominado mesoreto, assim como descrito por Sisson (1981, apud GETTY, 1986).
Discordando dos resultados encontrados por Garcia e Silva (2000) que encontraram em uma paca adulta de $4 \mathrm{Kg}$ as medidas de $40 \mathrm{~cm}$ para o ceco; $18 \mathrm{~cm}$ para região inicial do cólon; $26 \mathrm{~cm}$ para a parte reta do cólon; $180 \mathrm{~cm}$ para as regiões espiral e sigmóide do cólon; $72 \mathrm{~cm}$ para o reto e $16 \mathrm{~cm}$ para o ânus; nossos resultados foram de $32 \mathrm{~cm}$ para o ceco; $101 \mathrm{~cm}$ para o cólon maior; $12 \mathrm{~cm}$ para o cólon transverso, $234 \mathrm{~cm}$ para o cólon menor e $10,5 \mathrm{~cm}$ para o reto. Esta diferença pode ter ocorrido pela diferenciação na divisão dos segmentos do intestino grosso, as quais foram feitas de maneiras distintas em cada projeto.

Pode-se constatar que, em $100 \%$ das amostras analisadas, não houve variação no padrão de disposição do intestino grosso, e que este padrão se assemelha ao dos mamíferos em geral.

\section{Agradecimentos}

Os autores agradecem à Fundação de Amparo à Pesquisa do Estado de São Paulo (FAPESP) pela bolsa de iniciação científica (processo $n^{\circ}$ 01/14985-1R) concedida.

\section{Referências}

BANKS, R. The guinea pig: biology, care, identification, nomenclature, breeding, and genetics. 2002. Disponível em $<$ http:// www.netvet.wustl.edu/species/guinea/guinpig>. Acesso em: 23 dez. 2002.

BARONE, R.; PAVAUX, C.; BLIN, P. C.; CUQ, P. Atlas d'anatomie du lapin. Paris: Masson, 1986. 219 p.

BOWEN, R. The large intestine: introduction and index. 2002. Disponível em <http://www.arbl.cvmbs.colostate.edu/hbooks/ pathphys/digestion/largegut>. Acesso em: 22 dez. 2002.

BRESSAN, M. S.; FONSECA, C. C.; MENIN, E.; DE PAULA, T. A. R. Aspectos anátomo-histológicos e neuroendócrinos do ceco da capivara Hydrochoerus hydrocaeris Linnaeus, 1766 (Mammalia, Rodentia). Arquivos de Ciências Veterinárias e Zoologia da UNIPAR, Umuarama, v. 8, n. 2, p. 197-203, 2005.

CASTRO, T. F.; DUMMER, R. J.; RICKES, E. M.; PEREIRA, M. A. M. Aspectos morfológicos, morfométricos e topográficos do aparelho digestório de Chinchila lanígera. Brazilian Journal of Veterinary Research and Animal Science, São Paulo, v. 47, n. 1, p. 86-94, 2010.

COIMBRA FILHO, A. F. Situação mundial de recursos faunísticos na faixa intertropical. Brasil Florestal, Brasília, v. 17, p. 12-36, 1974. 
COLLET, S. F. Population characteristics of agouti paca (rodentia) in colombia. Biological Series, East Lansing, v. 5, n. 7, p. 601, 1981.

DYCE, K. M.; SACK, W. O.; WENSING, C. J. G. Tratado de anatomia veterinária. Rio de Janeiro: Editora Guanabara Koogan, 2010. $872 \mathrm{p}$.

GARCÍA, G. C.; SILVA, L. S. Aspectos morfológicos e histoquímicos del tubo digestivo de la lapa (Agouti paca) I. Histología. Revista Facultad de Ciencias Veterinarias, Maracay, v. 41, 4, p. 131-140, 2000.

GETTY, R. Aparelho digestório geral. In: SISSON, S.; GROSSMAN, J. D. (Ed.). Anatomia dos animais domésticos. Rio de Janeiro: Guanabara Koogan, 1986. p. 105-107.

JACKSON, T. P.; SPINKS, A. C. Gut morphology of the Otomyne rodents: an arid-mesic comparison. South African Journal of Zoology, Pretória, v. 33, n. 4, p. 236-240, 1998.

KLEIMAN, D. G.; EISENBERG, J. F.; MALINIAK, E. Reproductive parameters and productivity of caviomorph rodents. In: EISENBERG, J. F. (Ed.). Vertebrate ecology in the northern neotropics. Washington: Smithsonian Institution, 1979. p.173-183.

NICKEL, R.; SCHUMMER, A.; SEIFERLE, E.; SACK, W. O. The viscera of the domestic mammals. Berlin: Verlag Paul Parey, 1979. $401 \mathrm{p}$.

OLIVEIRA, F. S.; CANOLA, J. C.; MACHADO, M. R. F.; CAMARGO, M. H. B. Descrição anátomo-radiográfica do esqueleto axial da paca (Agouti paca, Linnaeus - 1766). Acta Scientiae Veterinariae, Porto Alegre, v. 34, suplemento 3, p. 331334,2006
QUIRILO, M. A.; CABRAL, V. P.; SIMONELLI, S. Avaliação morfométrica dos intestinos de coelhos domésticos da raça Nova Zelândia. Iniciação Científica CESUMAR, Maringá, v. 8, n. 1, p. 75-81, 2006.

RODBERTUS, A. Encyclopedia of Rodents. 2002. Disponível em $<$ http://40.1911 encyclopedia.org/r/ro/rodentia $>$. Acesso em: 23 dez. 2002.

SCHALLER, O. Illustrated Veterinary Anatomical Nomenclature. Stuttgart: Enke Verlag, 2007, 625p.

SCHWARZE, E.; SCHRÖDER, L. Compendio de anatomia veterinária. Zaragoza: Acribia, 1972. 315 p.

SIMMONS, Rat digestive system. 2002. Disponível em $<$ http:// www.uwinnipeg.ca/ simmons/lb8pg4.htm>. Acesso em: 10 abr. 2002.

SMALLWOOD, J. E. A guided tour of veterinary anatomy: domestic ungulates and laboratory mammals. Philadelphia: Saunders Company, 1992. 338 p.

VISPO, C.; HUME, I. D. The digestive tract and digestive function in the north-american porcupune and beaver. Canadian Journal of Zoology, Montreal, v. 73, n. 5, p. 967-974, 1995. 